\title{
Is the FOMC's Unemployment Rate Threshold a Good Idea?
}

Daniel L. Thornton, Vice President and Economic Adviser $\mathrm{t}$ its December 2012 meeting, the Federal Open Market Committee (FOMC) established a threshold of 6.5 percent for the unemployment rate by stating that it anticipates that the federal funds rate will remain exceptionally low "at least as long as the unemployment rate remains above $6-1 / 2$ percent." The establishment of this threshold is widely interpreted to mean that the FOMC will keep the funds rate target at effectively zero as long as the unemployment rate is higher than 6.5 percent. Some economists are skeptical of the usefulness of such a threshold because the unemployment rate is strongly affected by factors over which the FOMC has little or no control. This essay illustrates this point by showing the sensitivity of the unemployment rate to changes in the labor force participation rate (LFPR).

The unemployment rate is calculated from a monthly survey of households conducted by the U.S. Census Bureau for the Bureau of Labor Statistics (BLS). Basically, those surveyed are asked whether they are working or looking for work. Those working are considered employed; those looking for work are considered unemployed. Both are considered part of the labor force. The LFPR is the percent of civilian noninstitutional population in the labor force. The unemployment rate is the percent of the labor force unemployed.

The unemployment rate can decline because employment increases, the labor force declines, or both. The last possibility is illustrated by the November 2012 BLS report. From October to November the number of employed persons declined by 122,000 . If the labor force had remained the same, this reduction in employment alone would have caused the unemployment rate to increase by 0.078 percent. However, over the same period, the labor force declined by 350,000 persons, which caused the unemployment rate to decline by 0.207 percent. The net change in the unemployment rate was -0.129 percent, the sum of 0.078 percent and -0.207 percent. Note that this is equal to the difference between the October unemployment rate of 7.875 percent and the November unemployment rate of 7.746 percent.

How much of the decline in the unemployment rate since the end of the recent recession is due to a reduction in the labor force? One way to answer this question is to estimate what the unemployment rate would have been had the LFPR declined as it did after previous recessions. The first chart shows the LFPR since January 1948, with shaded bars indicating recessions. The LFPR tends to decline following recessions; however, for how long varies considerably across recessions. Moreover, the declines have been more pronounced following the past two recessions. The LFPR declined by 0.8 percentage points and 1.9 percentage points during the 41 months following the 2001 and 2007-09 recessions, respectively.

\section{The November 2012 unemployment rate would have been 1.6 percent higher had the labor force participation rate declined as it did following the 2001 recession.}

To see the extent to which the LFPR contributed to the decline in the unemployment rate following the most recent recession, I calculated what the unemployment rate would have been had the LFPR declined exactly as it did during the 41 months following the 2001 recession. The second chart shows this estimated (hypothetical) unemployment rate along with the actual unemployment rate and the difference between the two. The estimate indicates that the November 2012 unemployment rate would have been 1.6 percent higher had the LFPR declined as it did following the 2001 recession; that is, 9.3 percent rather than 7.7 percent. 
Given the sensitivity of the unemployment rate to the LFPR, it is not clear how long or how much employment will have to grow before the unemployment rate falls below the FOMC's threshold. For example, if the LFPR were to stabilize at 63.5 percent and both employment and the noninstitutional civilian population were to grow as they have since November 2010, the unemployment rate would be 6.9 percent by November 2014, significantly above the threshold rate. On the other hand, if the LFPR were to decline further, the threshold could be breached well in advance of that date. Of course, if the LFPR were to rise over the next two years, say because individuals began to reenter the labor force as employment opportunities improve, the federal funds rate could stay at zero considerably longer. In any event, some would argue that it may not be desirable to tie the stance of monetary policy to a rate so greatly affected by factors that policymakers have little or no control over.
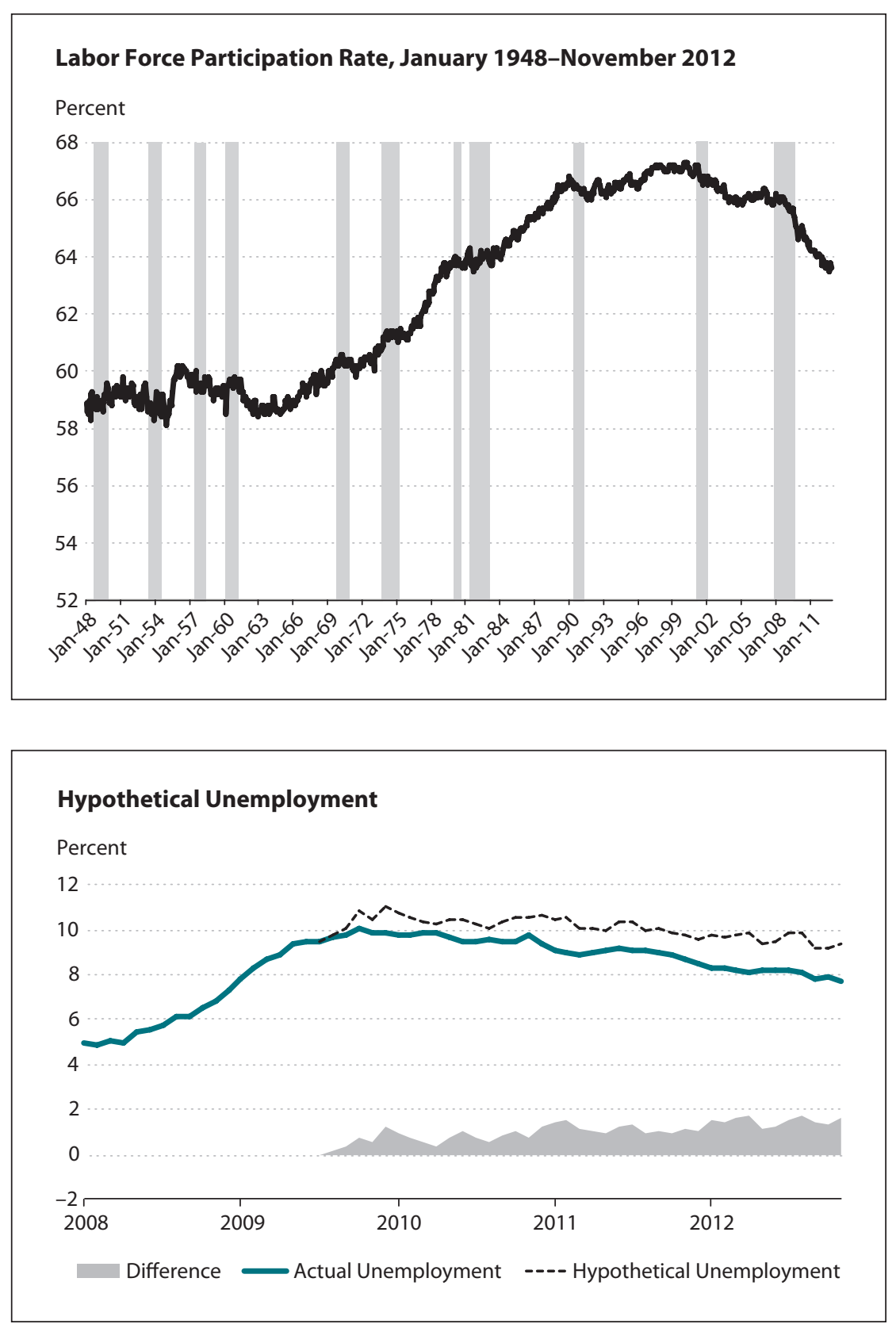